\title{
DEMETERRES project: development of innovative technologies for removing radionuclides from contaminated solid and liquid matrices.
}

\author{
Pierre Chagvardieff ${ }^{1}$, Yves Barré2 ${ }^{2}$ Virginie Blin ${ }^{3}$, Sylvain Faure ${ }^{2}$, Anne Fornier ${ }^{4}$, Didier Grange ${ }^{5}$, Agnès Grandjean², \\ Emmanuel Guiderdoni ${ }^{6}$, Pascale Henner ${ }^{7}$, Brice Siroux ${ }^{3}$, Antoine Leybros ${ }^{2}$, Marc Messalier ${ }^{8}$, Hervé Paillard ${ }^{5}$, Thierry \\ Prévost $^{8}$, Malvina Rennesson ${ }^{8}$, Catherine Sarrobert ${ }^{1}$, Alain Vavasseur ${ }^{1}$, Anne-Aliénor Véry ${ }^{9}$
}

${ }^{1}$ CEA DRF, 13108 St Paul lez Durance, France

${ }^{2}$ CEA DEN, 30207 Bagnols sur Cèze, France

${ }^{3}$ CEA DEN, 91192 Gif sur Yvette, France

${ }^{4}$ CEA DRF, 92265 Fontenay aux Roses Cedex, France

${ }^{5}$ VEOLIA 1 rue Giovanni Battista Pirelli, 94410 Saint Maurice, France

${ }^{6}$ CIRAD Boulevard de la Lironde, 34398 Montpellier cedex 5, France

${ }^{7} I R S N, 13108$ St Paul lez Durance, France

${ }^{8}$ AREVA 92084 Paris La Défense Cedex, France

IINRA, 2 place Pierre Viala, 34060 Montpellier Cedex 2, France

\begin{abstract}
As part of the «post-accidental» management, the DEMETERRES project (RSNR PIA) proposes to develop innovative and environmentally friendly methods for removal of cesium and strontium from soils and liquid matrices in order to rehabilitate them for an agricultural use while minimizing the volume of generated wastes in accordance with the nuclear waste existing processes. Complementary approaches are used: they are based on physico-chemical technologies (such as foams flotation, supercritical $\mathrm{CO}_{2}$ extraction, extractants in fluidized bed reactor ...) and biological ones (bioextractants, phytoextraction) which concepts are described. These researches aim to design innovative and performing extractants in term of selectivity and to achieve the pilot reactor phase for each of them. These pilots will group in a network to provide a technological platform lasting the project, to which will be attached an available network of experts. The respective advances of these researches are presented, completed of tests initiated in Japan on contaminated soils through partnerships.
\end{abstract}

\section{General context}

The restoration of the environment following a nuclear accident is a question of debate. For instance, soil decontamination by removing top soil as initiated in Fukushima prefecture will generate a considerable volume of organic wastes which can't address the existing nuclear waste treatment process capacities: innovative process of decontamination are likely to be developed. Similarly, the first tests using phytoextraction are just under investigation: this technology needs additional basic knowledge on soil-plant $\mathrm{Cs}$ and $\mathrm{Sr}$ transfer to become more successful. The DEMETERRES project (Development of bio- and eco- technologies for effluents and soils remediation in support to a restauration strategy following a nuclear accident) intends to study the feasibility at the pre-industrial stage of a set of environmentally friendly complementary technologies for rehabilitation of solid (soils) and liquid (fresh and seawater) matrices using both physico-chemical and biological approaches.
Some are suitable for ex-situ treatment of high contaminated wastes, others for in situ treatment of large volumes of weakly contaminated soils. This project, involving CEA, AREVA, VEOLIA, IRSN, INRA and CIRAD as partners, has been selected in 2013 by the French PIA (Programme Investissement d'Avenir) as part of the "Recherche en Sûreté Nucléaire et Radioprotection" RSNR call and will end by 2018.

The project aims to provide the actors in the postaccidental phase - firstly, with a decision-support guide bringing together the performances of technologies developed in regard to French soils $30 \mathrm{~km}$ around nuclear plants (NPP) - secondly, with a pre-industrial platform allowing to make available the developed pilots and associated with an expertise network. 


\section{Modelling the adsorption behavior of $\mathrm{Cs}^{+}$and $\mathrm{Sr}^{2+}$ onto a soil}

The main long-lasting radionuclides released into the environment as a result of a nuclear accident are Cs-137 and Sr-90. Prior to developing a decontamination strategy, one should understand the actual chemical state of radionuclides in the environment. This involves the understanding of the interactions of these radionuclides with the main compounds of soils: clay minerals, organic matter, bacteria, etc.

Cesium, as well as strontium, are strongly adsorbed in the upper horizon from a soil $(0-10 \mathrm{~cm})$, particularly on clay minerals [1]. This adsorption is controlled by different factors, such as the type of clay minerals (illite, smectite, vermiculite etc.) $[2,3]$, the presence of competitive ions $\left(\mathrm{Ca}^{2+}, \mathrm{Mg}^{2+}, \mathrm{K}^{+}, \mathrm{Na}^{+}\right.$, etc.) [4-6], the physical and chemical properties of the soil $(\mathrm{pH}$, ionic strength) [7], but also the presence of other compounds (carbonates, natural organic matter, etc.) [8,9]. Taking into account these factors, the CEA has developed a multisite ion-exchange model. Its objective is simulating the uptake of an element in naturally occurring mineral phases and under various conditions [10, 11].

Considering general knowledge on natural environments, the study has firstly been focused on clay minerals, especially the three most representative from the French agricultural soils, i.e. smectite, illite and kaolinite. A literature review and specific additional adsorption tests have allowed developing a consistent thermodynamic database compiling the selectivity coefficients for both major cations $\left(\mathrm{Ca}^{2+}, \mathrm{Mg}^{2+}, \mathrm{K}^{+}, \mathrm{Na}^{+}\right.$, $\mathrm{H}^{+}$) and trace elements (Cs, Sr) towards these pure clay minerals. The reversibility of this adsorption has been verified.

The robustness and efficiency of the model is then tested by carrying out adsorption tests onto mixtures of clay minerals (see an example for cesium in Fig.1).

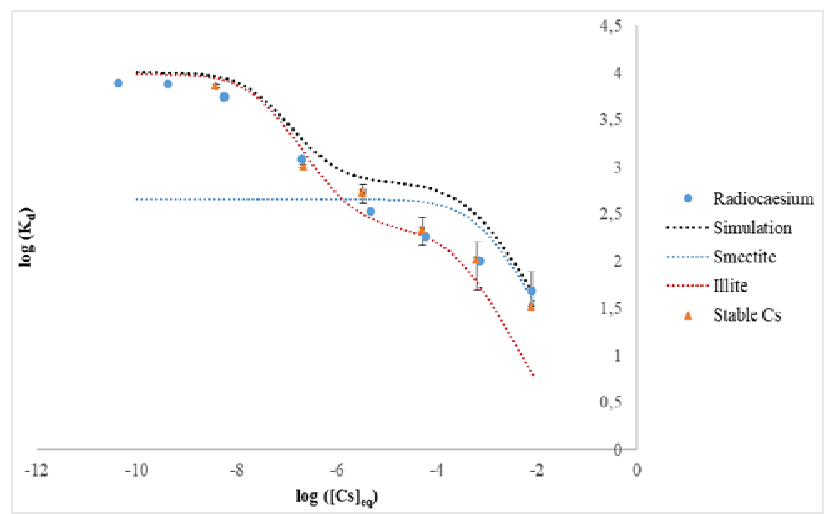

Fig. 1: Cesium adsorption isotherm on a mixture composed of $30 \%$ illite and $70 \%$ smectite $\left(\mathrm{K}_{\mathrm{d}}\right.$ : solid/solution distribution coefficient of cesium).

By comparing the experimental and simulated data, it is clear that cesium adsorption depends on its concentration. From the simulated curves, the contribution of illite to cesium adsorption is important at trace concentration and becomes less important at higher concentration. This is the direct consequence of illite having a smaller cationic exchange capacity than smectite, and higher affinity sites. However, an overestimation of the cesium adsorption is pointed out in the high concentration range, which should be further investigated. This kind of experiments allows verifying the model predictions and improves our understanding of the interactions involved in the adsorption processes of both cesium and strontium on clay minerals.

Parallel to these fundamental achievements, a physicochemical characterization of five French soils (representing $80 \%$ of the soils around the 20 target sites of the project: 19 Nuclear Power Plants and La Hague) was performed:

- CESTA (in the Bordeaux region).

- Étoile-sur-Rhône and Pusignan (region of the Rhône Valley).

- Digulleville and Herqueville (around La Hague).

It is then possible to verify and quantify the actual adsorption of cesium and strontium onto these soils in order to differentiate between adsorption mainly driven by clay minerals from the influence of other compounds, such as carbonates or natural organic matter.

The first results obtained using strontium and the Pusignan soil showed that experimental adsorption values and simulation are consistent. Though several approximations are used to simulate the strontium adsorption, the model succeeded in predicting the strontium uptake on Pusignan soil.

The results and understanding that will result from this study will be used in order to determine the most appropriate decontamination technologies regarding the type of contaminated soil.

\section{Ex situ soil decontamination}

For ex-situ soil remediation, two complementary physicochemical technologies are developed: the first one is designed for clay soils and is based on the removal of clay microparticles ( $<25$ microns) by a flotation foam process, the other one is devoted to sandy soils and rubles and is based on the extraction of the targeted radionuclide in supercritical $\mathrm{CO}_{2}$ as an organometallic complex ("contaminant - extractant " complex).

\subsection{Using particulate flotation foams}

Particulate flotation foams are of great interest in mineral processing, water treatment and could be used for Cs radioactive soil decontamination [12]. For Cs extraction, the proof of concept has been established at the laboratory scale using commercial clays (illite). Clays particle fixing Cs are floated thanks a suitable foaming and collecting surfactant. In 2015, a laboratory scale unit has been implemented (Fig2, Fig3) in order to study and to optimize the process parameters with clays (\% of surfactant, air injection rate, foam retention time...); measuring the overall extraction efficiency, selectivity and analyzing the size of the particles collected. Selectivity for the smallest clay particle size fraction (3 $\mu \mathrm{m})$ in foams was observed and correlated with foam height and drainage time (see figure 4 below) [13]. 


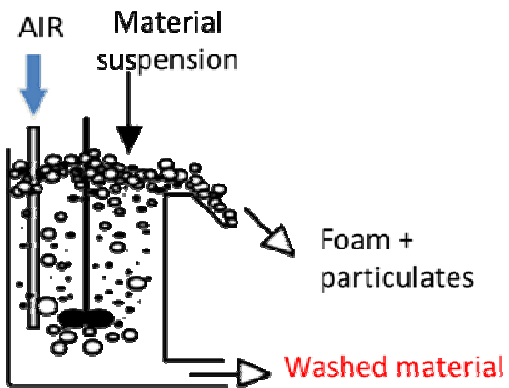

Fig 2: Principle of the particulate flotation foam process

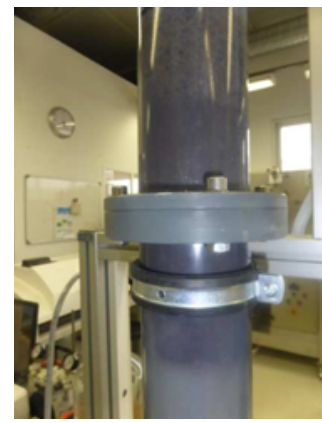

Fig 3: Foam building in a laboratory scale apparatus

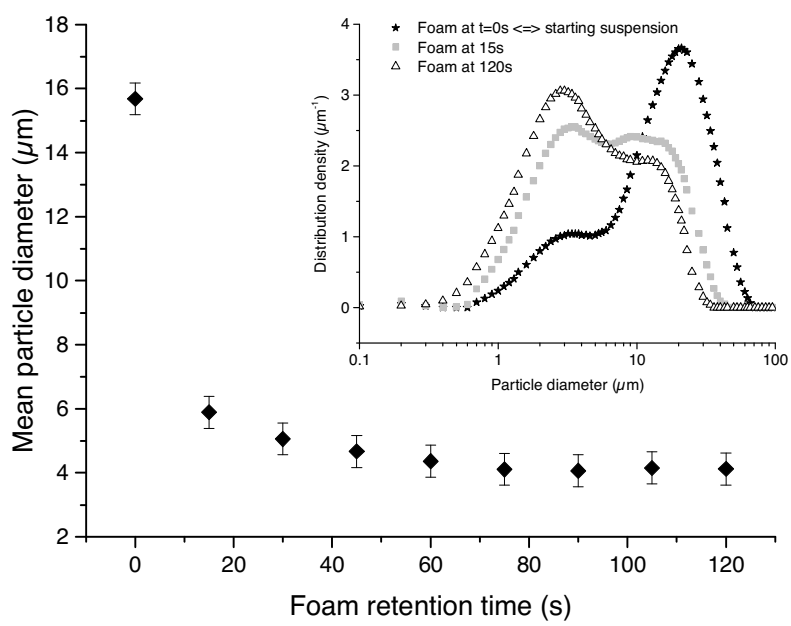

Fig 4: Mean particle diameter evolution with foam retention time in the foaming column. Size distributions at foam retention time of 0,15 and $120 \mathrm{~s}$

Tests with soils selected in the frame of the project have started and the first results are available. Preliminary pilot tests conducted in Japan on contaminated soils led to removal yields of the radioactive Cs close to $82 \%$ concentrated in 15 to $30 \%$ of the initial soil volume.

The fertility of treated soils will be tested after 3 months using a $50 \%-50 \% \mathrm{w} / \mathrm{w}$ mixture prepared with an untreated soil (simulating a plowing). In parallel, a study of the bacterial biodiversity is being performed on treated and untreated soils to test the possible influence of the clay particles content decrease on the treated soil.

\subsection{Using ionic flotation foam}

The potential of an ionic flotation foam process has been explored for the removal of ionic Cs. A screening of extracting components in combination with suitable surfactants has been achieved. A foam composition including Prussian blue analogs in the form of highly specific nanoparticles Cs [14] [15] has been shown to be efficient at the laboratory scale

\subsection{Using supercritical $\mathrm{CO}_{2}$}

Supercritical $\mathrm{CO}_{2}\left(\mathrm{SC}-\mathrm{CO}_{2}\right)$ extraction process is one of the promising, smooth technologies which may be applied to soil remediation. $\mathrm{SC}-\mathrm{CO}_{2}$ exhibits gas-like mass transfer rates with liquid-like solvating abilities. Moreover, its high diffusivity and low viscosity enable it to penetrate and transport solutes from porous solid matrices to the $\mathrm{SC}-\mathrm{CO}_{2}$ phase. Furthermore, its flexibility in terms of ability to adjust solvating power by tuning operating pressure and temperature is quite interesting.

Direct extraction of metal ions by $\mathrm{SC}-\mathrm{CO}_{2}$ is inefficient due to charge neutralization requirement and weak ionic solute-solvent interactions. Hence, organic ligands are needed to chelate ions and make them soluble in $\mathrm{SC}-\mathrm{CO}_{2}$. Successful $\mathrm{SC}-\mathrm{CO}_{2}$ extraction of alkali metal ions was carried out using macrocyclic compounds with perfluorocarboxylic acids such as HPFOA [16]. Crown ethers and calixarenes have been, in particular, studied for their selectivity towards cesium. Synergistic effects between macrocycles and HPFOA improve solubility due to CO2-philic HPFOA. Solubilities of all these compounds have been measured (Fig. 5) in our operating range using high pressure cells coupled with gravimetric and/or analytical methods in CEA Marcoule.

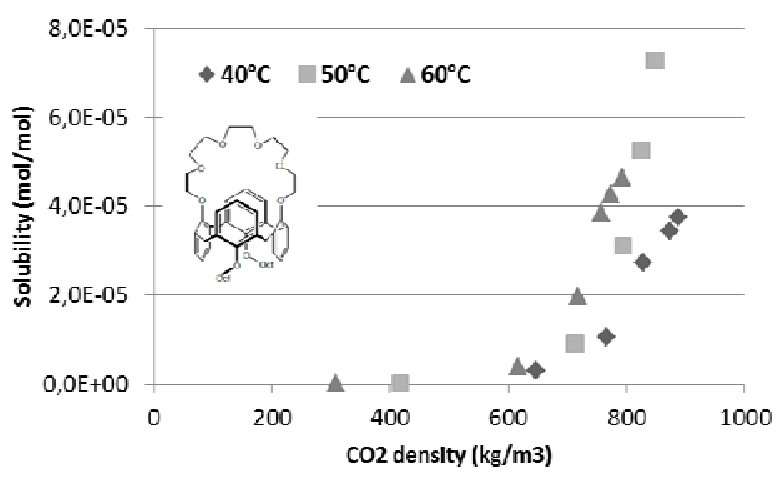

Fig 5: Example of solubility in supercritical $\mathrm{CO}_{2}$ profile for used macrocycle: 25, 27-Bis (1-octyloxy)calix[4]arene-crown6

Extraction set-up in batch dynamic mode is shown Fig.6. It includes a tank of $\mathrm{CO}_{2}$, a pump to reach operating flow rate, a heat exchanger to maintain work temperature and a back pressure regulator to maintain operating pressure. $\mathrm{CO}_{2}$ flows continuously through the 
sample in extraction reactor, before being released in collectors downstream from regulation valve. Csorganometallic complex is recovered in collectors.

Feasibility of $\mathrm{SC}-\mathrm{CO}_{2}$ extraction for decontamination of model silica soil has been studied with cesium contamination around $1 \mathrm{mg} \cdot \mathrm{g}^{-1}$ of soil using DB18C6/HPFOA extractant system. Process parameters influence such as operating pressure and temperature, extractant system amount, residual soil water content has been investigated in [17]. Low temperature $\left(40^{\circ} \mathrm{C}\right)$ and high pressure $(29 \mathrm{MPa})$ allow to optimize process ability for cesium removal. A compromise should be established, for a fixed $\mathrm{CO}_{2}$ flow rate, between amounts of extractants and cationic exchanger. Moreover, residual moisture of silica soil plays a significant role concerning cesium extraction. By considering all these parameters, extraction yields up to $95.5 \%$ were obtained and demonstrated our concept.

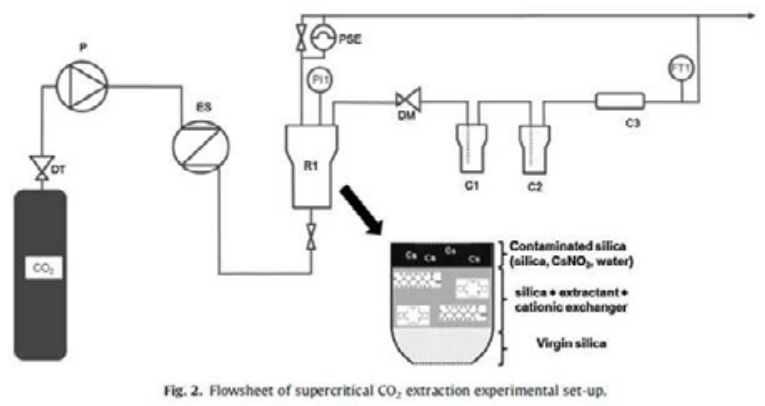

Fig 6: Principle of radionuclides extraction from sand and rubbles using supercritical $\mathrm{CO}_{2}$

Further experimental runs with realistic cesium contamination content are in progress using ${ }^{137} \mathrm{Cs}$ in nuclear laboratory using gamma spectroscopy. In these runs, modified calixarene-crowns whose solubility was determined in our operating range will be used due to better selectivity towards radiocesium. These extractants have been functionalized to increase their solubility in $\mathrm{SC}-\mathrm{CO}_{2}$, while maintaining higher selectivity towards cesium.

\section{In situ soil remediation}

In situ restoration of contaminated soils can be achieved by phytoremediation. A drawback of this technic is a long term achievement and that it can only be performed on soils with low or medium levels of contamination. Yet, it appears complementary of ex situ remediation that stays the only way of treatment for heavy levels of contamination. Cesium (Cs) and strontium (Sr) are analogues of potassium $(\mathrm{K})$ and calcium $(\mathrm{Ca})$, respectively. The phytoextraction process is based on the transport of radionuclides in planta using plant transporters mechanisms usually dedicated to plant nutrition (Fig. 7). The first assays done in Japan have revealed a need for further understanding to enhance the capacity of plants to uptake and translocate $\mathrm{Cs}$ and $\mathrm{Sr}$. Various strategies essentially based on genetic approaches are developed.

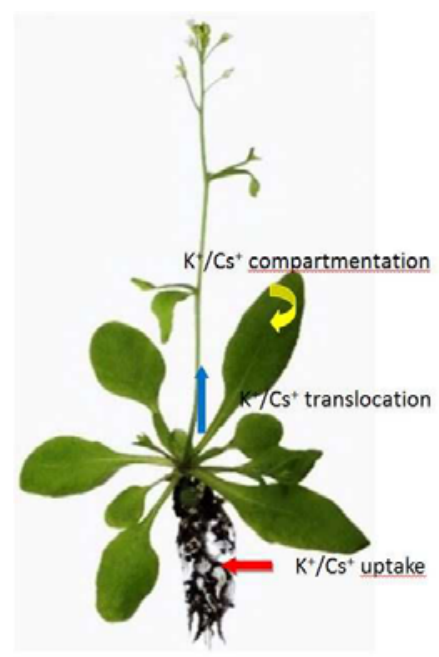

Fig 7: Phytoextraction principle

\subsection{Fit the root architecture to the contamination profile}

Adaptation of roots architecture to the contaminated zone, e.g. managing root architecture to locate the roots mainly in the first $10 \mathrm{~cm}$, is a way to increase the yield of phytoextraction of radio-Cs. Conversely, deep rooting is a way to diminish the uptake of surface contaminant such as Cs. For that purpose, different genes have been targeted in Rice, which regulate the angle of development of secondary roots [18] (Fig 8). Work is now underway to characterize the impact of Rice roots architecture on Cs uptake and translocation using contaminated soils from Fukushima's area and artificial substrates based on perlite which mimics clay with a determined gradient of $\mathrm{Cs}$ contamination.

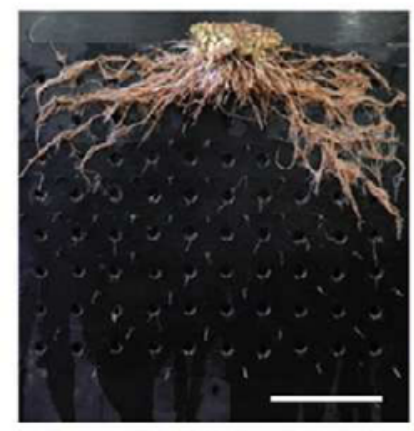

IR64

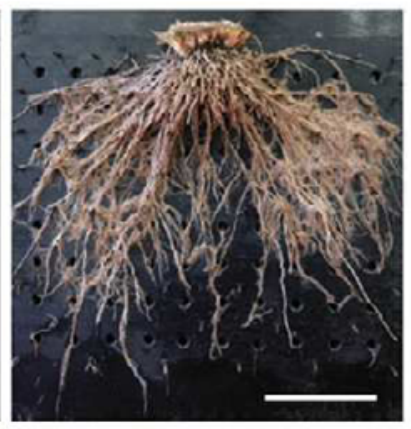

Dro1-NIL
Fig 8: Rice lines with different roots architecture 


\subsection{Increase the radionuclides phyto-availability}

Some substrates exuded by roots such as organic acids and protons are well-known to increase the phytoavailability of minerals such as $\mathrm{Fe}$ or $\mathrm{Al}$ by modifying their chemical speciation. We are studying a way to control organic acids and protons exudation by means of genetics, targeting genes that control these processes at the level of transporters and transcription factors in Arabidopsis thaliana. Validation of this concept is underway using contaminated soils from Fukushima's area.

\subsection{Increase the uptake and translocation of radionuclides}

Different plant transporters able to uptake K but also Cs have been identified in Arabidopsis thaliana and Rice. Depending on the genes considered, knock-out lines exhibited in hydroponic conditions a change in the transfer of radio-cesium to shoots from $+200 \%$ to $-50 \%$ when compared to the wild plant. These lines will be tested on contaminated soils and the corresponding genes targeted in agronomic crops to increase (phytoextraction) or decrease (safe-food) the transfer of radionuclides.

Due to chemical analogies and based on competition studies, Cs uptake in plants has been shown to proceed mainly by $\mathrm{K}$ transporters and to be potentially submitted to $\mathrm{K}$ homeostasis. In Arabidopsis thaliana as much as 90100 genes are putative $\mathrm{K}$ transporters, some of them described for $\mathrm{K}$ uptake and a minority described as being able or not to also transport Cs. We tested candidates from different families of $\mathrm{K}$ transporters regarding their performances in $\mathrm{K}$ transport as detailed on Fig. 7, in particular for families in which at least one gene has been shown to respond to Cs. A screening of numerous knockout lines of these potentially interesting candidates had been performed through Cs toxicity response assessment by germination test in liquid medium containing Cs and various levels of $\mathrm{K}$. Lines whose response was different from reference plant (e.g. Fig 9.a, wild type ecotype ColumbiaO shows greener seedlings than mutant $\mathrm{A}$ after exposure to Cs)- tentatively because of different Cs accumulation level, were furtherly tested. If interest was confirmed at the end of the screening phase, Cs uptake and translocation experiments were performed (e.g. Fig 9.b., mutant A accumulated more Cs in leaves after 7 days than reference plant). In the following mutants are labelled by letters as description of their performance is still not totally published.

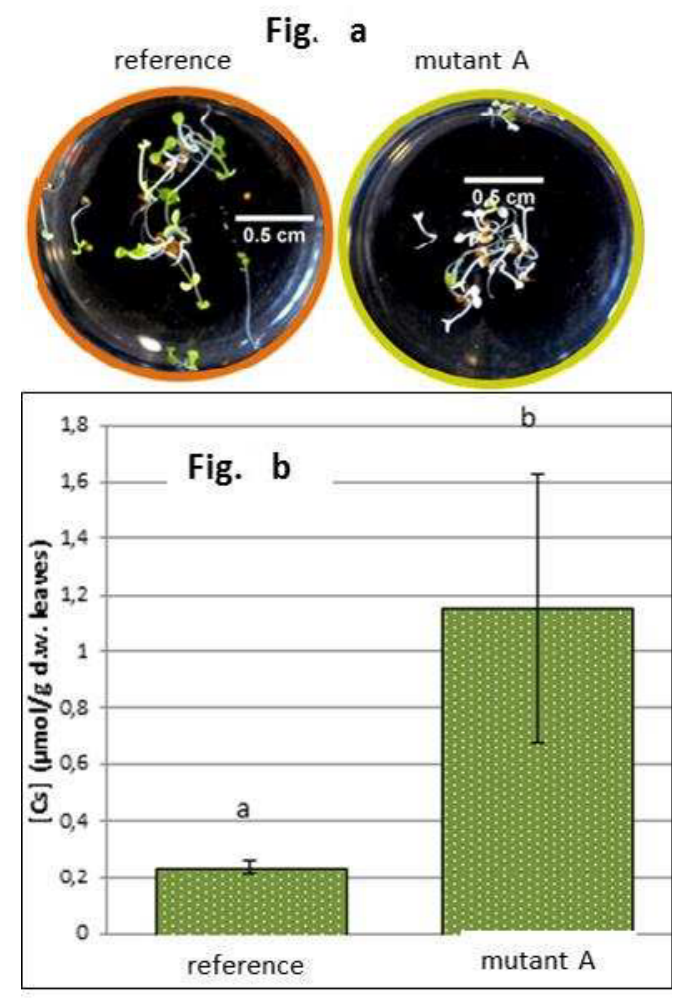

Fig 9: a) Cs toxicity in germinated seedlings and 7-days-Cs b) accumulation in 35 days old plants of mutant line A affected (knocked-out) in a $\mathrm{K}$ transporter compared to reference line Col0. Fig. 9a- $100 \mu \mathrm{M}$ K and $300 \mu \mathrm{M}$ Cs; Fig. 9b. $100 \mu \mathrm{M} \mathrm{K}$ and $1 \mu \mathrm{M} \mathrm{Cs}$.

Studies are under way for the full characterization of gene $\mathrm{A}$ and mutant performances regarding $\mathrm{K}$ and $\mathrm{Cs}$ uptake and translocation. Also are under way the first experiments testing these mutants using contaminated soils from Fukushima's area

\subsection{The safe-food approach}

When soils present a moderate contamination another strategy may be applied, it consists in growing plants with a limited capability to transfer Cs from the soils to the plant tissues. Such criterion depends on genetics determinants. This approach was started using Rice and targeting $\mathrm{K}$ transporters from KUP/HAK/KT and HKT families, most likely candidates to behave a high affinity transport of Cs. As previously mentioned, K transporters are numerous in plants and a first assay was heterologous expression in yeast in order to determine the selectivity of the encoded transporters concerning $\mathrm{K}$ and $\mathrm{Cs}$, respectively. A mutant yeast line deficient in the main $\mathrm{K}$ transporters was used, trk1 trk2 tokl. Yeast growth was followed in the presence of various $\mathrm{K}$ and Cs concentrations coupled with the determination of Cs and $\mathrm{K}$ uptake by yeast transformed lines. This approach showed that several members exhibited a large permeability to Cs. However, when expressed in Xenopus oocytes, only one Rice transporter exhibited a high affinity transport of Cs. Work is now on the way to characterize the role of this transporter in planta using reverse genetics. 


\section{Liquid matrices decontamination}

Decontamination of liquid matrices requires the development of extractants selective of $\mathrm{Cs} / \mathrm{Sr}$ and economically acceptable as a way for developing technologies adapted to a «post-accidental» situation (mobility, maintenance...). Selective extraction on nonrecycled support in columns (high performance selectivity) or fluidized-bed (multi-decontamination) pilot reactors is studied on two liquid matrices templates: freshwater and seawater. Two approaches are under progress to develop extractants selective of Cs and/or Sr.

\subsection{Development of new chemical extractants}

In this context a selective adsorbent material for $\mathrm{Cs}$ (SORBMATECH ${ }^{\circledR} \quad 202, \quad$ S202) was developed, consisting of potassium/copper ferrocyanide nanoparticles deposited in the mesoporosity of silica grains. This material is designed for column process due to its average grain size of $450 \mu \mathrm{m}$. Several batch experiments were carried out in order to obtain kinetic and thermodynamic data of the ion exchange. Kinetic experiment showed that the sorption equilibrium is reached in less than $5 \mathrm{~min}$. Fast sorption kinetics is a significant asset for use in column.

Distribution coefficients $\mathrm{K}_{\mathrm{d}, \mathrm{Cs}}$ were calculated for each of the isotherm experiments, as a function of $\mathrm{Cs}^{+}$ remaining in solution. Isotherms performed with radioactive ${ }^{137} \mathrm{Cs}$ (pure water at $\mathrm{pH} 7$, fresh water and seawater) were also used to calculate $\mathrm{K}_{\mathrm{d}, \mathrm{Cs}}$ for very low Cs concentration. Each $\mathrm{K}_{\mathrm{d}, \mathrm{Cs}}$ point is reported in 0. At low $\mathrm{Cs}^{+}$concentrations, the competitive ion effect is comparatively more effective: $\mathrm{K}_{\mathrm{d}, \mathrm{Cs}}$ is about $2.5 \times 10^{6}$ $\mathrm{mL} / \mathrm{g}$ at $\mathrm{pH}=7$ without competitive cation but decreases by one order of magnitude in seawater $\left(\mathrm{K}_{\mathrm{d}}=2 \times 10^{5}\right.$ $\mathrm{mL} / \mathrm{g}$ ). The same behavior was observed for fresh water, although the lower concentration of competitive cations than in seawater leads to $K_{d}$ close to the one in pure water $\left(\mathrm{K}_{\mathrm{d}}=10^{6} \mathrm{~mL} / \mathrm{g}\right)$. Despite these competitive effects, this material is undoubtedly a good candidate to decontaminate seawater effluent contaminated with traces of ${ }^{137} \mathrm{Cs}$.

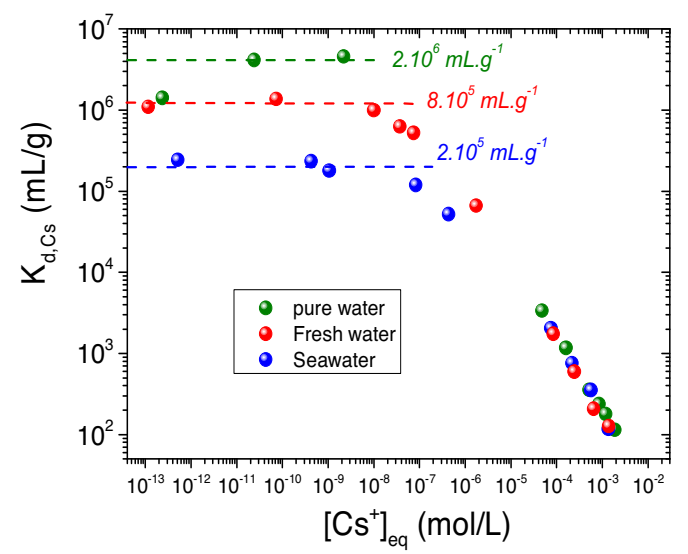

Fig.10: Variation of $\mathrm{K}_{\mathrm{d}, \mathrm{Cs}}$ as a function of $\left[\mathrm{Cs}^{+}\right]_{\mathrm{eq}}$ for different type of aqueous solutions.
Column experiments were performed using a microcolumn of $1 \mathrm{~cm}$ diameter and $10 \mathrm{~cm}$ high. The same amounts of material were put in the column and represented a bed height of $5 \mathrm{~cm}$. A fresh water containing $0.5 \mathrm{mmol} / \mathrm{L}$ of $\mathrm{CsNO}_{3}$ passed through this column at two different flow rates $(20 \mathrm{BV} / \mathrm{h}$ and 200 $\mathrm{BV} / \mathrm{h}$ ). The breakthrough curves are reported on Figure 11, where no difference was observed between these two flow rates. Moreover, these breakthrough curves are typical of fast diffusion kinetic in the column with no detachment observed even at high flow rate.

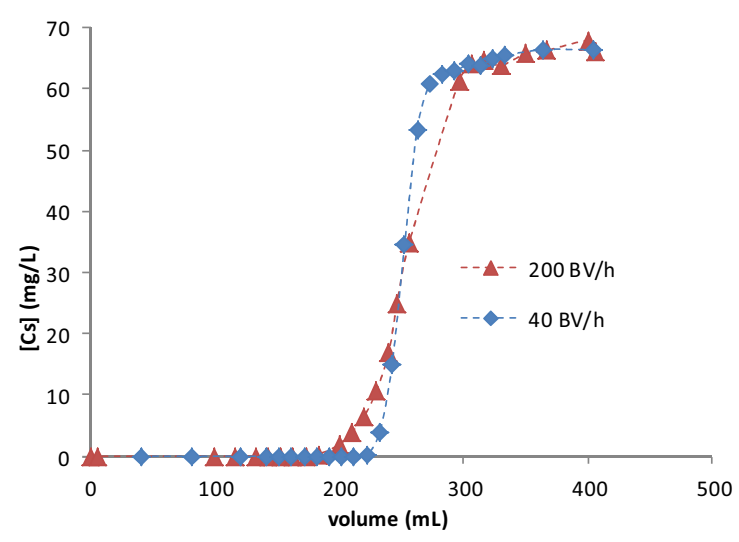

Fig.11: Breakthrough curves at $40 \mathrm{BV} / \mathrm{h}$ and $200 \mathrm{BV} / \mathrm{h}$ under same operational conditions $\left(\mathrm{H}_{\mathrm{bed}}=5 \mathrm{~cm}\right.$, freshwater, $[\mathrm{Cs}]=70$ $\mathrm{mg} / \mathrm{L})$

In Fukushima, the selective sorbents used to extract ${ }^{90} \mathrm{Sr}$ include sodium titanates and/or zeolites. However, ${ }^{90} \mathrm{Sr}$ removal efficiency by these ion exchange minerals is significantly reduced by high contents of competitive cations $(\mathrm{Ca}, \mathrm{Mg})$ and non-radioactive strontium isotopes in seawater. Traditionally, in the radioactive liquid effluent treatment plants, barium sulfate is used to remove radioactive strontium from effluents by a continuous coprecipitation process [19]. This process is selective but leads to large volumes of radioactive sludge that have to be managed. To address these concerns, our approach consists in coupling ion exchange and coprecipitation processes. A barium titanate material coupled with a precipitation with sulfate ions has proved to be an effective and selective sorbent for extraction of strontium from effluents of high salinity like seawater. This coupling demonstrates considerably high capacity and selectivity for strontium extraction with distribution coefficients $\mathrm{K}_{\mathrm{d}}$ of $18200 \mathrm{~mL} / \mathrm{g}$, obtained from batch sorption tests with seawater enriched with ${ }^{90} \mathrm{Sr}(59355$ $\mathrm{Bq} / \mathrm{L}, \mathrm{m} / \mathrm{V}=5 \mathrm{~g} / \mathrm{L}$ ). As evidenced by SEM-EDX pictures in Figure 12, the precipitation of $\mathrm{BaSO}_{4}$ occurs at the surface of the titanate grains. However, $\mathrm{Sr}$ ions seem uniformly distributed in the $\mathrm{BaSO}_{4}$ crystals and in the titanate grains. Therefore, the possible mechanism of $\mathrm{Sr}$ extraction involves the ion exchange with the $\mathrm{Ba}$ ions from the material and a coprecipitation of insoluble barium sulfate crystals formed at the surface of the titanate grains upon contact with the effluent containing sulfate ions. 

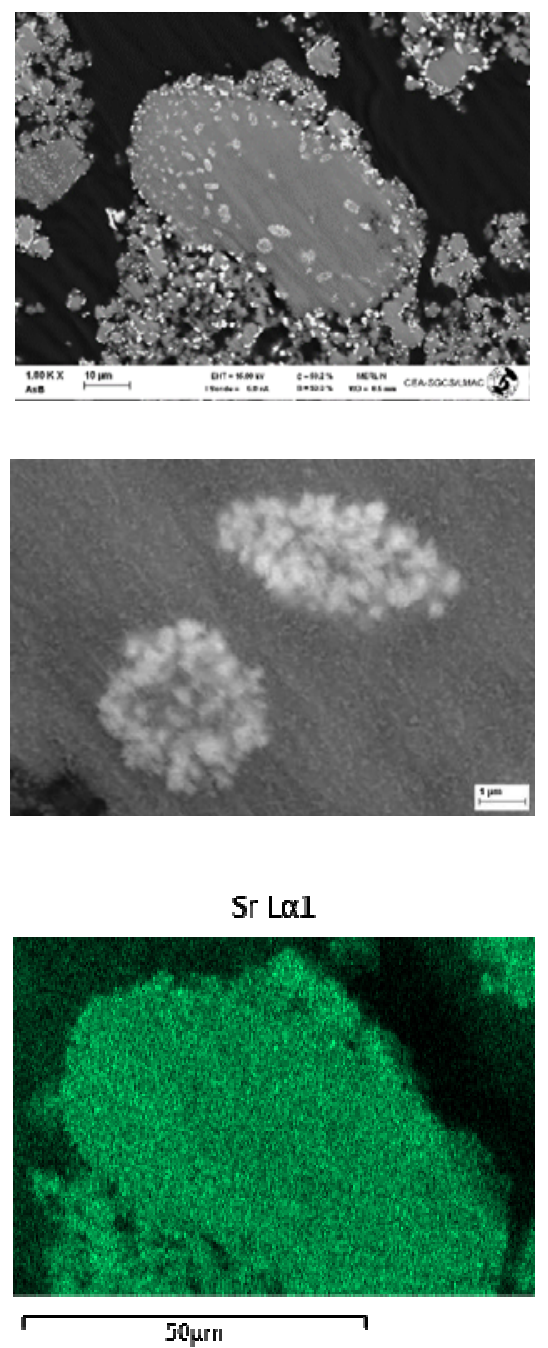

Fig. 12: SEM-EDX images of the barium titanate after a $24 \mathrm{~h}$ contact with a solution of $\mathrm{Sr}\left(\mathrm{NO}_{3}\right)_{2}\left(\left[\mathrm{Sr}^{2+}\right]=8 \mathrm{mg} / \mathrm{L}\right)$ in $\mathrm{Na}_{2} \mathrm{SO}_{4}$ $\left(\left[\mathrm{SO}_{4}{ }^{2-}\right]=2,7 \mathrm{~g} / \mathrm{L}\right)$

\subsection{Drawing inspiration from living world to design innovative extractants}

Some biological molecules, such as calmodulin, have a strong affinity for calcium, a strontium analog. Some peptides have been designed from the chelating domains (EF Hand) of calmodulin and are optimized after mutagenesis. Uranium-chelating peptides had previously been obtained using this approach [20]. Measurement of $\mathrm{Sr}$ affinity to screen the modified peptides (Fig 13) is made by fluorimetry. They will be further modified to increase their capacity to chelate Cs.

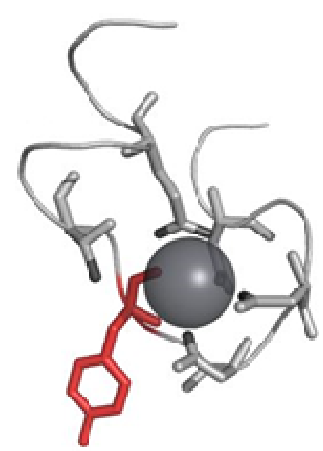

Fig 13: Modification (in red color) of a chelating domain of calmodulin to increase $\mathrm{Sr}$ affinity

Microorganisms (particularly soil bacteria) are also screened in presence of $\mathrm{Sr}$ or Cs to select strains with a high capacity of accumulation. From the first experiments, realized by incubating bacteria strains during $24 \mathrm{~h}$ in freshwater containing $50 \mathrm{mg} / \mathrm{L} \mathrm{Sr}$, a strain accumulating $50 \%$ of $\mathrm{Sr}$ has been isolated. These bacteria could be then used directly in bioreactors.

\subsection{Mobile fluidized-bed pilot reactor}

The fluidized-bed SAPHIRA ${ }^{\mathrm{TM}}$ technology developed by VEOLIA has been optimized and tested by AREVA / VEOLIA with water doped with $\mathrm{Cs}$ and $\mathrm{Sr}$ between November 2015 and March 2016.

Cesium is adsorbed with ferrocyanide salt. It is a 20 $\mathrm{g} / \mathrm{L}$ suspension injected in the SAPHIRA ${ }^{\mathrm{TM}}$. During last week of trial, a specific adsorbant developpped by CEA / AREVA has been tested: SORBMATECH ${ }^{\mathrm{TM}}$. Basically, it is ferrocyanide salt linked to zeolithe which has the same adsorption properties as ferrocyanide salt but is easier to put in use (heavier: settling is better). Strontium is adsorbed by the precipitation of fresh $\mathrm{BaSO}_{4}$ caused by the mixing in the SAPHIRA ${ }^{\mathrm{TM}}$ of $\mathrm{Ba}\left(\mathrm{NO}_{3}\right)_{2}$ and $\mathrm{Na}_{2} \mathrm{SO}_{4}$. This co-adsorption is currently performed in La Hague in a standard coagulation/flocculation facility. The main difference with SAPHIRA ${ }^{\mathrm{TM}}$ is the use of a single reactor, the absence of sludge recirculation and, therefore, the low sludge concentration within the equipment.

In DEMETERRES project the purpose is to develop a nuclearized, compact equipment which could be used in case of emergency after a nuclear accident.

\subsubsection{SAPHIRA ${ }^{\mathrm{TM}}$ Pilot}

The SAPHIRATM pilot ran at $300 \mathrm{~L} / \mathrm{h}$. Hydraulic retention time was 60 minutes within the reactor.

Potable water was doped in line with $5 \mathrm{ppm} \mathrm{Cs}$ and $\mathrm{Sr}$ (injection of concentrated solutions) and treated in the SAPHIRA ${ }^{\mathrm{TM}}$. Apart of ferrocyanide salt and $\mathrm{BaSO}_{4}$, we also injected flocculant and sometimes coagulant in order to retain TSS (Total Suspended Solids). $\mathrm{BaSO}_{4}$ was not problematic but ferrocyanide salt settled badly without the aid of coagulant and flocculant.

SAPHIRA $^{\text {TM }}$ was operated between 40 and $60 \mathrm{~g} / \mathrm{L}$ TSS at the inlet of the reactor. The produced sludge was stored in cubitainers and incinerated: no dehydratation of sludge tested. 


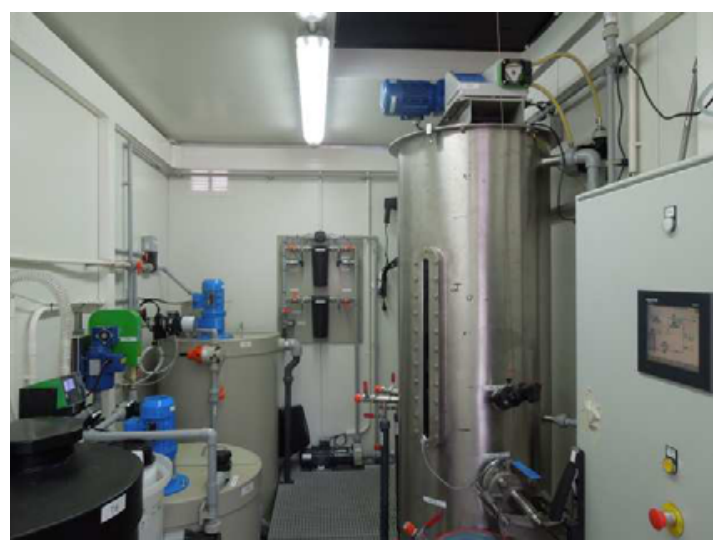

Fig 14: SAPHIRA ${ }^{\mathrm{TM}}$ pilot unit

\subsubsection{Cesium adsorption by ferrocyanide salt}

Decontamination factor ([Cs]initial/[Cs]out; known as "FD") is presented below (Fig 15). A decontamination factor of 100 means $99 \%$ removal yield. A dose of 50 ppm of ferrocyanide was kept for the tests

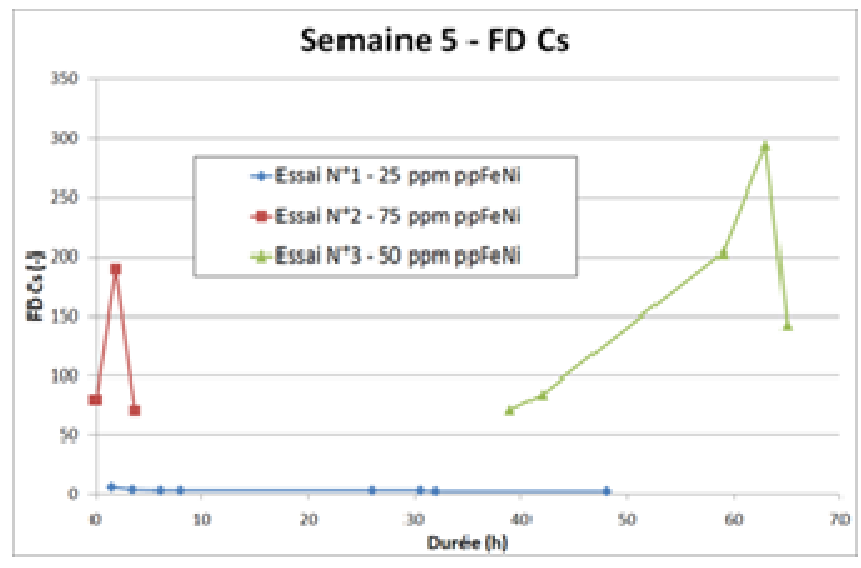

Fig 15: Cs Decontamination Factor according to the ferrocyanide concentration

Ferrocyanide salt is difficult to settle in the SAPHIRA $^{\text {TM }}$ because is very fine (around 10 microns). Small doses of coagulant and flocculant really help settling: At the outlet of the reactor the turbidity decreases from 60 NTU without, down to 10 NTU. With ferrocyanide and to achieve a $\mathrm{FD}_{\mathrm{Cs}}$ of 70 it is necessary to inject a flocculant and set up a $20 \mu \mathrm{m}$ filter. With the SORBMATECHTM $\mathrm{FD}_{\mathrm{Cs}}$ is lower (20) but it is not necessary to inject flocculant.

The performances are limited due to the Cs concentration during inactive test. Higher DF could be expected with radioactive effluent.

\subsubsection{Strontium adsorption by $\mathrm{BaSO}_{4}$}

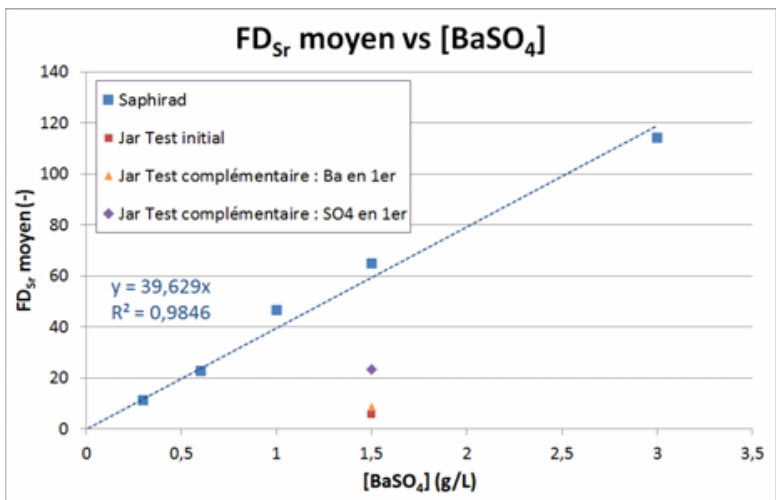

Fig 16: Sr Decontamination Factor according to the $\mathrm{BaSO}_{4}$ concentration

The decontamination factor is around 60 with $1,5 \mathrm{~g} / \mathrm{L}$ $\mathrm{BaSO}_{4}$ precipitated. It is less efficient than cesium adsorption with ferrocyanide salt but this kind of result was expected. Results on the pilot are better than in jartesting which would tend to prove that the sludge blanket has a positive effect. The mean $\mathrm{FD}_{\mathrm{Sr}}$ at $1.5 \mathrm{~g} / \mathrm{L}$ is 60 which means $98 \%$ removal yield.

$\mathrm{BaSO}_{4}$ precipitates and settles well in the SAPHIRA ${ }^{\mathrm{TM}}$. The improvement of $\mathrm{FD}_{\mathrm{Sr}}$ is also possible by increasing the concentration of the sludge bed in the reactor

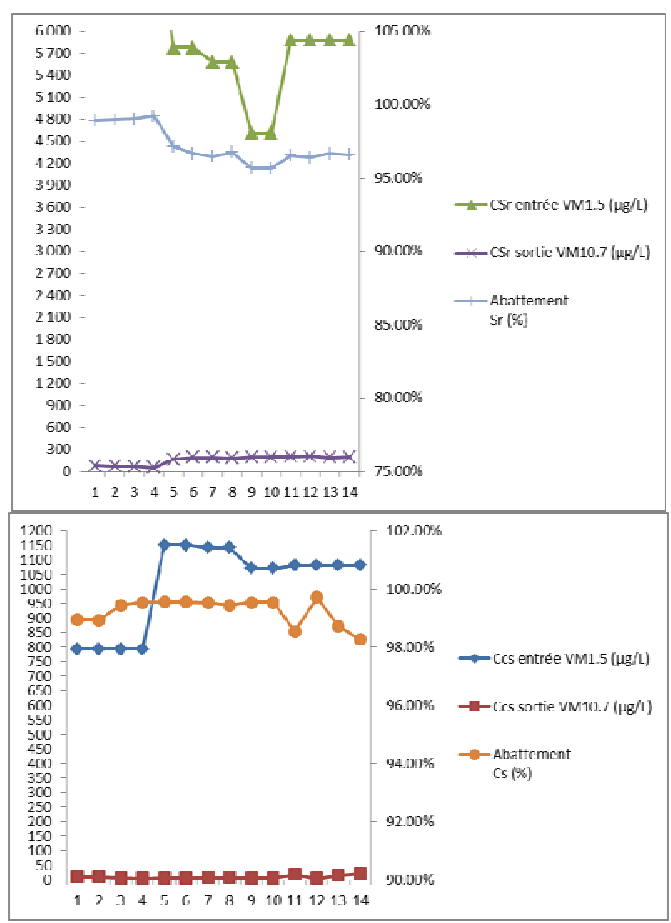

Fig 17: Simultaneous average abatement of Cs and Sr with $\mathrm{BaSO}_{4}$

Average $97 \%$ for $\mathrm{Sr}(\mathrm{FD}=51)$ and average $99 \%$ for $\mathrm{Cs}$ $(\mathrm{FD}=166)$ 


\subsection{Mobile riser pilot reactor}

Preconditioned or immersed ion-exchange columns have been developed. Pilot reactors of increasing capacity have been tested. SORBMATECH ${ }^{\mathrm{TM}}$ feasibility assessment in large-capacity reactor required a previous production of several $\mathrm{kg}$. A prototype of the NYMPHEA technology engineered by AREVA has been completed and tested. Its 1:1 scale-up is being evaluated.

\section{Operational implementation of the project}

On one part, a guidance for remediation of contaminated territories, leaning on the performances of the developed technologies, will be drafted. This guidance will integrate the soil analysis realized upstream to the project to define the typologies of grounds around the target sites. A further perspective is a decision-making tool for remediation strategies, integrating also REX of experimented technologies, and leaning on a multicriteria methodology taking into account social and societal stakes in territories recovery.

On the other part, a preindustrial platform will be rigged, to make available access to the pilots developed within the framework of the project, both for the actors of the post-accidental phase and for new applications (extraction of other radionuclides, heavy metals...). To this platform will be associated an expertise network which could be mobilized in post-accidental situation and a set of trainings to perpetuate the implementation of processes and hardware.

\section{Acknowledgements}

The authors thank the French «Programme Investissement d'Avenir » (ANR-11-RSNR-0005 DEMETERRES) managed by the National Research Agency (ANR) for its financial support.

\section{References}

1 H. Amano, T. Matsunaga, S. Nagao, Y. Hanzawa, M. Watanabe, T. Ueno, Y. Onuma, Org. Geochem. 30, 437 (1999)

2 M.H. Bradbury, B. Baeyens, J. Contam. Hydrol. 42, $141(2000)$

3 X. Chen, S. Peng, J. Wang, J. Radioanal. Nucl. Chem. 303, 509 (2015)

4 P. Jacquier, J. Ly, C. Beaucaire, Appl. Clay Sci. 26, 163 (2004)

5 T Missana, M. García-Gutiérrez, Phys. Chem. Earth 32, 559 (2007)
6 T. Missana, A. Benedicto, M. García-Gutiérrez, U. Alonso, Geochim. Cosmochim. Acta 128, 266 (2014)

$7 \quad$ P.K. Verma, P. Pathak, P.K. Mohapatra, Radiochim. Acta 102, 401 (2014)

8 C. Dumat, S. Staunton, J. Environ. Radioact. 46, 187 (1999)

9 M. Samadfam, T. Jintoku, S. Sato, H. Ohashi, J. Nucl. Sci. Technol. 37, 180 (2000)

10 E. Reinoso-Maset, J. Ly, J. Chem. Eng. Data 59, 4000 (2014)

11 S. Savoye, C. Beaucaire, B. Grenut, A. Fayette, Appl. Geochem. 61, 41 (2015)

12 Faure, S.; Messalier. M., Patent WO2013167728 A1. (2013)

13 Chapelain, J. C. M.; Faure, S.; Beneventi, D., Clay Flotation: Effect of TTAB Cationic Surfactant on Foaming and Stability of Illite Clay Microaggregates Foams. Ind Eng Chem Res, 55 (7), 2191-2201 (2016)

14 C. Micheau, P. Bauduin, O. Diat, Patent CEA WO2015063073 (2014)

15 D. Dedovets, P. Bauduin, J. Causse, L. Girard, O. Diat, Phys. Chem. Chem. Phys. 18, 3188-3196 (2016)

16 S. Mochizuki, N. Wada, R. Smith Jr, H. Inomata, Anal. Commun. 36 :51-52 (1999)

17 A. Leybros, A. Grandjean, N. Segond, M. Messalier, O. Boutin, J. Environ. Chem. Eng. 4 :1076-1080 (2016)

18 N. Ahmadi, A. Audebert, MJ. Bennett A. Bishopp , A. Costa de Oliveira , B. Courtois , A. Diedhiou, A. Diévart , P. Gantet, A. Ghesquière , E. Guiderdoni, A. Henry, Y. Inukai, L. Kochian, L. Laplaze, M. Lucas, D. Trung Luu, B. Manneh, X. Mo, R. Muthurajan, C. Périn, A. Price, S. Robin, H. Sentenac, B. Sine, Y. Uga, AA. Véry, M. Wissuwa, Ping Wu and J. Xu Rice 7:29 (2014)

19 V. Pacary, Y. Barré, E. Plasari, Method for the prediction of nuclear waste solution decontamination by coprecipitation of strontium ions with barium sulphate using the experimental data obtained in non-radioactive environment, Chemical Engineering Research and Design, 88 (2010) 1142-1147.

20 MR. Beccia, S. Sauge-Merle, D. Lemaire, N. Bremond, R. Pardoux, S. Blangy, P. Guilbaud, C.Berthomieu J biol. Inorg. Chem., 20(5): 905 - 19 (2015) 